\title{
Cultural Pluralism and Social Connectedness as Predictors of Immigrant Students' Social Wellbeing and Achievements
}

\author{
Abubakar $\mathrm{HM}^{1}$ \\ Insitut Agama Islam Negeri Palangka Raya, Palangka Raya, Indonesia
}

\begin{abstract}
Based on the utmost importance of respecting cultural differences to foster learning among immigrant students from diverse cultures and grounded in Social Psychology Theory, this study investigates the impact of cultural pluralism and social connectedness on immigrant students' achievement through social wellbeing. Moreover, the contingent impact of perceived discrimination in decreasing the positive influence of students' social wellbeing has been assessed. This study advances the body of literature regarding cultural diversity as well as the importance of cultural pluralism and social connectedness in promoting social wellbeing to enhance the achievements of immigrant students. Applying a time-lagged survey methodology, data were collected from the 323 immigrant students from the universities located at Kalimantan Island of Indonesia. Data were analyzed using SmartPLS software. The results revealed the positive impact of cultural pluralism and social connectedness on immigrant students' social wellbeing leading to high achievements. Results also showed that the positive influence of immigrant students' social wellbeing on their achievements decreases in the presence of perceived discrimination as a moderator.
\end{abstract}

Keywords: cultural pluralism, perceived discrimination, social connectedness, social wellbeing, students' achievement.

At higher education institutions, immigrant students have to prove themselves in various platforms and acquire key competencies in multiple areas (Smith et al., 2020; Dalle \& Ariffin, 2018). For instance, they achieve academic success and develop core competencies in their field of study (Sun et al., 2021). Moreover, they have to face migration-specific challenges particularly linked with steering among two or more cultures and dealing with discrimination (Motti-Stefanidi, 2018). In addition to that, the role of educational institutions in handling cultural diversity is of immense importance (Makrooni \& Ropo, 2021). A successful approach in dealing with cultural diversity and facilitating students to excel in various fields regardless of their country of origin creates a climate of cultural pluralism (Dengechi et al., 2021; Dalle, Hairudinor, et al., 2020).Moreover, an environment of cultural pluralism captures a climate where cultural group differences are respected by providing adequate opportunities for learning to students with different cultural backgrounds (Schachner et al., 2019). Although, the importance of cultural pluralism climate in developing and enhancing immigrant students' psychological adjustments and reducing depression and anxiety has been well explored (Celeste et al., 2019; Schachner et al., 2019; Sun et al., 2021; Wasike, 2017). However, researchers have identified knowledge gaps and highlighted the importance of studying cultural pluralism's direct and indirect impacts on student achievement by identifying the underlying mechanisms in different contexts and cultures (Oczlon et al., 2021; Smith et al., 2020; Dalle et al., 2021).

\footnotetext{
${ }^{1}$ Corresponding Author E-Mail: dr.h.abubakar.hm@gmail.com
} 
Hence, to bridge this gap, the current study investigates the impact of cultural pluralism on immigrant student achievement utilizing social wellbeing as a mediator.

In addition, social connectedness depicts the internal sense of belongingness and is conceptualized as an individuals' understanding/perception of being in close association with the social world (Lee \& Robbins, 1995). This close relationship with the social world may include friends, family, peers, society, and community (Liu, 2019; Dalle, Siyoto, et al., 2020). Research shows the impact of social connectedness in reducing stress and anxiety among individuals belonging to different ethnic backgrounds (Bender et al., 2019) by promoting a sense of social integration (Sun et al., 2021). However, to the best of the authors' knowledge, the impact of social connectedness on students' achievement through an underlying mechanism of wellbeing has received less attention from recent scholars.

The literature shows that wellbeing comprises various factors, i.e., emotional fulfillment, complying with ones' commitments, satisfaction with work, and life (Diener \& Scollon, 2003). The social wellbeing linked with students' quality of life, performance, and satisfaction with the educational institution based on the host country culture and social support has been considered in recent research (Dengechi et al., 2021). Prior studies demonstrate various life events, including relocation and migration, as predictors of wellbeing (Luhmann et al., 2012). The current study is incremental by examining the impact of cultural pluralism and social connectedness on immigrant students' social wellbeing and their resultant achievements.

Furthermore, despite these positive factors that promote harmony and connectedness among immigrant students, some factors negatively impact student achievement (Filippello et al., 2020; Li, 2020; Oczlon et al., 2021). Perceived discrimination between immigrants and nonimmigrant students based on diverse cultural backgrounds is among those negative factors (Sun et al., 2021). Research shows that diversity of culture increases perceptions of discrimination among immigrant students (Brenick et al., 2018). The literature also reveals the negative impact of perceived discrimination on students' performance, satisfaction, and achievement (Banks, 2015; Oczlon et al., 2021). However, the literature lacks evidence regarding the contingent effect of perceived discrimination to observe the decreasing impact of wellbeing on students' sense of achievement. Therefore, this research studied the moderating role of perceived discrimination.

The current study is established on social psychological theory, demonstrating the impact of individuals' perceptions and social relationships on their wellbeing and achievements. In addition, the authors attempt to advances social psychology theory by integrating the positive and negative constructs, i.e., cultural pluralism, social connectedness, wellbeing, achievement, and perceived discrimination, in a single comprehensive framework in a cultural diversity context. Moreover, the current study is conducted in the Indonesian context, where immigrants are distributed all over the country (Hutabarat, 2020). Also, based on the limited studies available regarding the impact of various cultural factors on immigrant students' outcomes (Wahid et al., 2020), it is appropriate to examine cultural factors that impact immigrant students' wellbeing and achievement in Indonesian educational institutions. Hence, established in the social psychological theory, the current study

- Do cultural pluralism, social connectedness, and social wellbeing impact immigrant students' achievement?

- Does immigrant students' social wellbeing mediate the association of cultural pluralism and social connectedness with their achievement?

- Does perceived discrimination moderate the association of immigrant students' social wellbeing with their achievement? 


\section{Theoretical Foundation and Literature Review}

\section{Cultural Pluralism, Social Connectedness, Social Wellbeing, and Achievement}

Cultural pluralism has been considered a broader approach, covering student-student and student-teacher interactions in educational institutions' contexts (Papadopoulou et al., 2020). The cultural pluralism approach emerged from a multicultural perspective to promote and acknowledge intercultural differences, considering diversity a valuable resource (Banks, 2015). Research also reveals the importance of the "equality and inclusion" approach, which focuses on reducing the differences among ethnic groups and promoting intergroup contacts (Hysa, 2020; Schachner et al., 2016). Scholars also linked both approaches with various student outcomes (Schachner et al., 2019; Yamamori, 2019).

Moreover, in a study related to immigrant students' context, Oczlon et al. (2021) reveal the importance of cultural pluralism in enhancing students' academic achievements. Besides, students' social wellbeing has been conceptualized as satisfaction with self, school experience, and relationships based on a sustainable positive attitude and mood (Binfet, 2017). Despite the immense importance of cultural pluralism climate in predicting positive student outcomes (Oczlon et al., 2021; Schachner et al., 2016; Smith et al., 2020), research lacks evidence regarding the association of cultural pluralism with immigrant students' social wellbeing. Therefore, to address the literature gap and established in social psychological theory, it can be stated that cultural pluralism plays a positive role in addressing cultural diversity and creating a productive learning environment. Hence it is hypothesized that;

H1a: There is a positive association between cultural pluralism and immigrant students' achievement.

H2a: There is a positive association between cultural pluralism and immigrant students' social wellbeing.

Previously in immigrant students' context, achievement has been studied as an outcome of cultural pluralism, motivation, psychological adoption, etc. (Kim et al., 2020; Oczlon et al., 2021; Oweis, 2018; Schotte et al., 2018). Besides, social connectedness has been studied in the context of the host community, the ethnic community, or both (Cojuharenco et al., 2016; Stone \& Logan, 2018; Sun et al., 2021). Ethnic social connectedness involves achieving a sense of social belongingness and integration, whereas intercultural social connectedness involves protecting international/immigrant students against discrimination or negative outcomes (Wei et al., 2015). Likewise, the literature also depicts the importance of social connection in deriving positive outcomes like satisfaction and motivation to learn among immigrant students (Chen et al., 2021; Luczak \& Kalbag, 2018). The current study is rooted in social psychological theory and posit the following hypotheses;

H1b: There is a positive association between social connectedness and immigrant students' achievement.

H2b: There is a positive association between social connectedness and immigrant students' social wellbeing.

\section{Social Wellbeing and Achievement}

Social wellbeing has been defined as "the evaluation we make of circumstances and functioning within society” (Keyes, 1998, p. 127). It has been linked with a feeling of attachment and relevance in the social world (Keyes, 2006). Research shows the importance of 
students' wellbeing in enhancing trust and commitment with the studies (López et al., 2017). It has been studied previously as an antecedent of students' success and satisfaction (Samad et al., 2019). Moreover, social wellbeing has been considered a more accurate measure of students' academic success based on its features to determine the students' perceptions about the social health of the school (Dengechi et al., 2021). Students' achievement encompasses their academic grades, teachers' positive evaluation, and promotions to the next grades (Li, 2020). Based on the above literature and social psychological theory following hypothesis has been proposed;

H3: There is a positive association between social wellbeing and immigrant students' achievement.

\section{Social Wellbeing as a Mediator}

Students' academic success has been reported as dependent upon the positive classroom climate (Wang et al., 2020). Scholars have linked cultural pluralism with immigrant students' academic achievement (Celeste et al., 2019; Sawatsuk et al., 2018; Schachner et al., 2019). Despite these studies, which proved the positive impact of cultural pluralism on students' academic achievements, the underlying mechanisms between the two constructs have been scarcely explored (Oczlon et al., 2021). Previously, school belongingness and students' selfesteem have been studied as mediators between cultural pluralism and achievement (Oczlon et al., 2021; Schachner et al., 2019). In comparison, the mediating role of students' social wellbeing was considered in the current study. Literature shows the impact of various life events on an individuals' wellbeing (Luhmann et al., 2012). Specifically considering the college and university students, their social wellbeing depends on the level of adjustment (Aliyyah et al., 2020; Locks et al., 2008). Moreover, wellbeing has been reported as an important predictor of students' performance, satisfaction with studies and educational institutions, enhanced learning, and goal accomplishments (Binfet, 2017; Nedal \& Alcoriza, 2018; Wang et al., 2020).

Grounded in the literature and theory of social psychology, two approaches are considered to deal with the cultural diversity of immigrant students (Hysa, 2020; Wu \& Ida, 2018). The first one deals with reducing the negative impacts of cultural diversity, whereas the other focuses on enhancing the positive outcomes (Hachfeld et al., 2011). The focus of the current study is examining the positive outcomes of this diversity based on the cultural pluralism and social connectedness leading to students' achievement via an underlying mechanism of social wellbeing. Hence, the following hypotheses are proposed;

H4a: Immigrant students' social wellbeing mediates the association between cultural pluralism and achievement.

H4b: Immigrant students' social wellbeing mediates the association between social connectedness and achievement.

\section{Perceived Discrimination as a Moderator}

Perceived discrimination represents the immigrant students' perception of prejudicial or unjust treatment based on the difference in country of origin and belongingness to a different culture (Wei et al., 2015). Students' social wellbeing represents students' positive attitude and satisfaction with the academic activities and positive experiences at school (Newton et al., 2021). The literature demonstrates the positive association of wellbeing with students' academic success (Samad et al., 2019). Moreover, research shows the negative impact of perceived 
discrimination on students life satisfaction (Benita, 2021), achievement (Guerra et al., 2019), and mental health (Sun et al., 2021; Wei et al., 2015). Furthermore, (Wei et al., 2015) previously examined the moderating role of perceived discrimination in between the association of students' mental health and achievement. In contrast, its role between wellbeing and achievement has not been explored earlier. This research advances by bridging this gap. Hence, it has been hypothesized that;

H1b: Perceived discrimination moderates the association of immigrant students' social wellbeing with their achievement such that the association is stronger in the case of a low level of perceived discrimination.

\section{Theoretical Framework of the Study}

The theoretical framework of the current study is developed based on social psychological theory. The theory advocates that individuals' perceptions and social relationships impact their wellbeing and achievements. Hence in the current study context, it is asserted that the practices of cultural pluralism and social connectedness together enhance the immigrant students' wellbeing, further leading to their enhanced achievements. Besides, the authors attempt to advances social psychology theory by integrating the positive and negative constructs, i.e., cultural pluralism, social connectedness, wellbeing, achievement, and perceived discrimination, in a single comprehensive framework in a cultural diversity context. Moreover, figure 1 presents the theoretical framework of the study.

Figure 1

Theoretical Framework of the Study

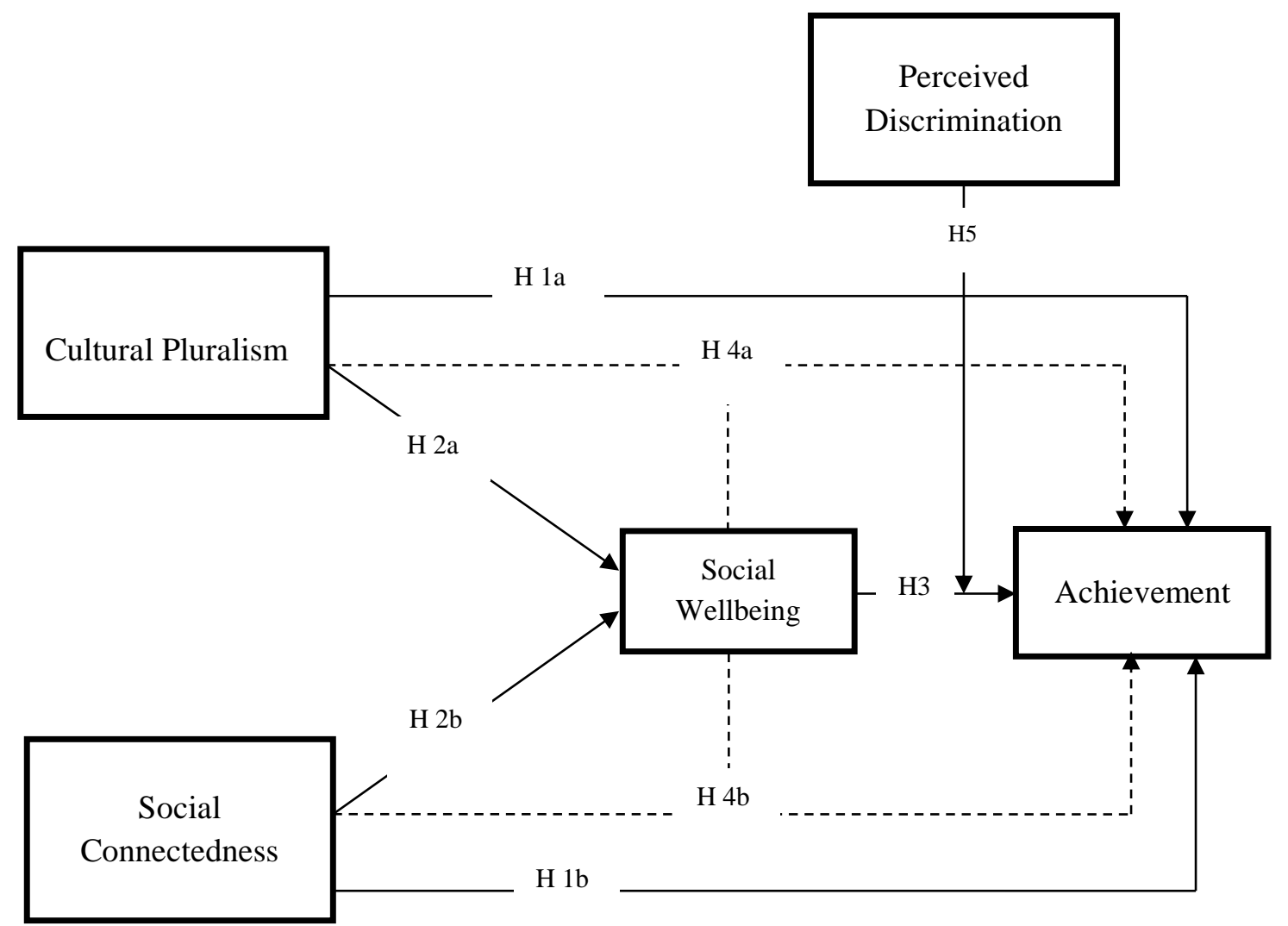




\section{Research Design}

\section{Participants and Context of the Study}

To examine the direct and indirect impact of cultural pluralism and social connectedness on immigrant students' achievement via social wellbeing as a mediator, the current study was conducted among the immigrant students studying at different universities at Kalimantan Island of Indonesia. According to 2019 statistics, there were approximately 353,140 immigrants in Indonesia (Hutabarat, 2020), and research shows that immigrant students are widely distributed among the whole country (Karyanta, 2021). Two criteria were considered for the inclusion of respondents in this study: either immigrant students were born in a country other than Indonesia, or both parents were born in a country other than Indonesia (second generation).

\section{Data Collection Procedures}

Using a time-lagged quantitative survey approach, primary data were gathered from immigrant students studying at different higher education institutions and universities at Kalimantan Island of Indonesia. In the first stage, the institutions and universities in Kalimantan Island were identified. The universities' research ethics boards and management were then contacted to get information about the number of immigrant students in each college and university. In total, the authors approached sixteen institutions and eight universities. They were requested to permit researchers to contact the students belonging to different nationalities. In the second stage, after getting permission to contact and collect data from immigrant students, researchers approached students and ensured the anonymity of the information. In total, 480 students agreed to participate in the survey. As the survey language was English, the study used adopted scales in the original form to avoid translation and back translation issues, which helped avoid response and common method biases.

The data collection procedure started on January 3, 2021. In Time 1 survey, a questionnaire comprised of two parts, i.e., one related to the demographic characteristics of the students, and the second part comprised items related to the three study constructs, i.e., cultural pluralism, social connectedness, and social well-being handed over to the students. This process continued for six weeks. The authors received 410 usable responses in Time 1 survey. After six weeks of the Time 1 survey, students were contacted again on April 1,2021, and were requested to participate in the Time 2 survey consisting of items related to perceived discrimination and students' achievements. In Time 2 survey, authors received 323 usable responses representing the $67.29 \%$ final response rate.

Students reported 43 different countries where either they or one of their parents were born. Our sample consisted of 323 students with an immigrant background. $61.7 \%$ of the respondents were male, and $38.3 \%$ were females. The age of the respondents varied from $16-$ 26 years $($ Mean $=21.2$ years, $\mathrm{SD}=1.02) .33 .8 \%$ of respondents were studying at higher education institutions, and $66.2 \%$ were studying at universities. $22.9 \%$ were studying at an undergraduate level, $26.2 \%$ at the graduate level, and $37.4 \%$ were studying at postgraduate levels. 


\section{Measures of the Study}

Students' social wellbeing was measured with 7-items adapted from the social wellbeing scale that Manuela and Sibley (2015) developed. Social connectedness was measured with an 8-item scale adapted from Lee and Robbins (1995). Cultural pluralism was measured with 3items adapted from Schachner et al. (2016). All these constructs were measured as " $1=$ strongly disagree to $5=$ strongly agree." Perceived discrimination was measured with 3 -items adapted from Brenick et al. (2018). Perceived discrimination was measured as " $1=$ never to $5=$ very often". Finally, the process that Oczlon et al. (2021) used was followed to measure the students' achievement. Students were requested to report their most recent grades for three subjects (depending upon the specialization of the students), which were averaged across the three subjects and used as indicators of achievement. Responses were recorded as " $1=$ lowest grade and $5=$ best grade."

\section{Data Analysis and Results}

\section{Measurement Model}

\section{Table 1}

Factor Loadings, Reliability, and Validity

\begin{tabular}{|c|c|c|c|c|c|c|c|c|}
\hline Constructs/indicators & & Fac & or Loac & ggs & & AVE & CR & CA \\
\hline & 1 & 2 & 3 & 4 & 5 & & & \\
\hline Cultural Pluralism & & & & & & 0.590 & 0.811 & 0.792 \\
\hline CP1 & 0.714 & & & & & & & \\
\hline $\mathrm{CP} 2$ & 0.816 & & & & & & & \\
\hline CP3 & 0.770 & & & & & & & \\
\hline Social Connectedness & & & & & & 0.574 & 0.915 & 0.856 \\
\hline $\mathrm{SC} 1$ & & 0.779 & & & & & & \\
\hline $\mathrm{SC} 2$ & & 0.752 & & & & & & \\
\hline $\mathrm{SC} 3$ & & 0.771 & & & & & & \\
\hline $\mathrm{SC} 4$ & & 0.724 & & & & & & \\
\hline SC5 & & 0.807 & & & & & & \\
\hline SC6 & & 0.730 & & & & & & \\
\hline SC7 & & 0.733 & & & & & & \\
\hline $\mathrm{SC} 8$ & & 0.762 & & & & & & \\
\hline Social Wellbeing & & & & & & 0.567 & 0.901 & 0.842 \\
\hline WB1 & & & 0.726 & & & & & \\
\hline WB2 & & & 0.805 & & & & & \\
\hline WB3 & & & 0.728 & & & & & \\
\hline WB4 & & & 0.720 & & & & & \\
\hline WB5 & & & 0.734 & & & & & \\
\hline WB6 & & & 0.828 & & & & & \\
\hline WB7 & & & 0.723 & & & & & \\
\hline Achievement & & & & & & 0.559 & 0.792 & 0.778 \\
\hline $\mathrm{ACH} 1$ & & & & 0.754 & & & & \\
\hline $\mathrm{ACH} 2$ & & & & 0.726 & & & & \\
\hline $\mathrm{ACH} 3$ & & & & 0.763 & & & & \\
\hline Perceived Discrimination & & & & & & 0.673 & 0.860 & 0.816 \\
\hline PD1 & & & & & 0.781 & & & \\
\hline PD2 & & & & & 0.826 & & & \\
\hline PD3 & & & & & 0.852 & & & \\
\hline
\end{tabular}

Note: $\mathrm{CR}=$ composite reliability, and AVE $=$ average variance extracted. 
SmartPLS3 software was used for analysis purposes. Results revealed that respondents' gender had a significant impact on their achievement. Therefore, gender was controlled in further analyses. Cronbach's $\alpha(\mathrm{CA})$ and composite reliability (CR) were calculated to assess the reliability of measures (Henseler et al., 2009; Mansoor \& Noor, 2019). Table 1 shows the values of CA (above 0.70 ) and CR. For all other indicator variables, factor loadings were greater than 0.70 , and the average variance extracted (AVE) of latent variables was above 0.50 for all study constructs; hence, convergent validity was established (Mansoor, 2021b; Sueca et al., 2021).

Researchers reported the Heterotrait-Monotrait (HTMT) ratio as the most appropriate measure of discriminate validity (Henseler et al., 2015; Noor et al., 2021). The HTMT ratio was then the cut-off value, i.e., 0.9 for the entire model (see Table 2).

Table 2

Heterotrait-Monotrait Ratio

\begin{tabular}{lccccccc}
\hline \multicolumn{1}{c}{ Constructs } & Mean & STD. & $\mathbf{1}$ & $\mathbf{2}$ & $\mathbf{3}$ & $\mathbf{4}$ & $\mathbf{5}$ \\
\hline Cultural Pluralism & 4.12 & 0.80 & $\mathbf{0 . 7 6 8}$ & & & & \\
Social Connectedness & 3.96 & 0.89 & 0.413 & $\mathbf{0 . 7 5 7}$ & & & \\
Social Wellbeing & 3.92 & 0.91 & 0.521 & 0.534 & $\mathbf{0 . 7 5 2}$ & & \\
Achievement & 4.09 & 0.83 & 0.517 & 0.407 & 0.471 & $\mathbf{0 . 7 4 7}$ & \\
Perceived Discrimination & 3.87 & 1.01 & 0.423 & 0.419 & 0.327 & 0.379 & $\mathbf{0 . 8 2 0}$ \\
\hline
\end{tabular}

Note: The square roots of AVEs of the constructs are shown in bold in diagonal.

Figure 2

Full Measurement Model

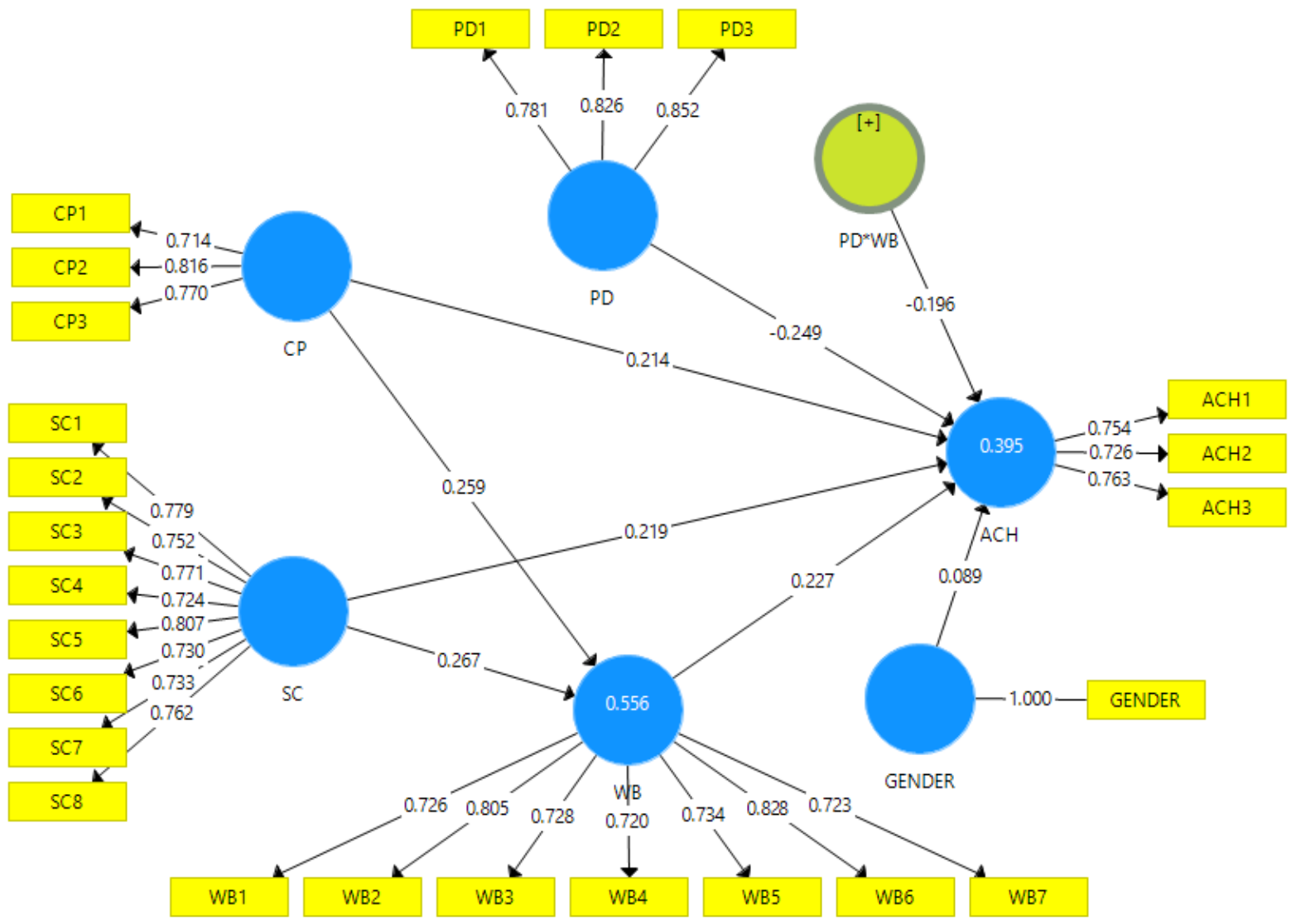




\section{Structural Model and Hypothesized Paths}

The bootstrapping technique was performed to assess the structural paths, and 500 subsamples were used to test the hypothesized links (Mansoor, 2021a). B-coefficient, $t$-value, and $p$-value were recorded to confirm the hypothesized relationships. Simultaneously, the Coefficient of Determination $\left(R^{2}\right)$ depicted a $61.3 \%$ change in the achievement due to all direct variables and mediating variables. $R^{2}$ values reflect good model fitness. Moreover, Table 3 shows the results of the direct as well as an indirect hypothesis. Results reveal a positive and significant association of $C P\left(\beta=.214^{* * *}, t=4.262\right), S C\left(\beta=.219^{* * *}, t=4.345\right)$, and $W B(\beta$ $=.227 * * *, t=4.807)$ with students' achievement. Similarly, results also showed a positive and significant association of $C P(\beta=.259 * * *, t=5.659)$ and $S C(\beta=.267 * * *, t=5.737))$ with $W B$. Therefore, the results supported hypotheses $\mathrm{H} 1 \mathrm{a}, \mathrm{b}, \mathrm{H} 2 \mathrm{a}, \mathrm{b}$, and $\mathrm{H} 3$ of the current study. The significance levels are shown in Figure 4.

The mediation hypotheses $\mathrm{H} 4 \mathrm{a}$ and $\mathrm{b}$ were also supported. An indirect and positive effect of $C P\left(\beta=.201^{* *}, t=4.087\right)$ and $S C\left(\beta=.238^{* * *}, t=5.124\right)$ with $A C H$ in the presence of $W B$ as mediator was proved true. In addition, the predictor indicator approach in SmartPLS3 was used to calculate interaction terms between PD and WB to examine its effect on students' $A C H$. The results indicated in Table 3 shows a significant and negative effect of interaction terms, $\mathrm{PD} * \mathrm{WB}$, on $\mathrm{ACH}\left(\left(\beta=-0.196^{* *}, t=3.871\right)\right.$. The $R^{2}$ for students' achievement with the moderating effect of PD decreased to $R^{2}=0.395$ from $R^{2}=0.613$. The $R^{2}$ change suggested that the inclusion of an interaction term decreased the explanatory power of achievement among students by $21.8 \%$. Moreover, results are explained through plotted moderation graphs.

Figure 3

Interaction Plots for the Moderating Effect of $P D^{*} W B$

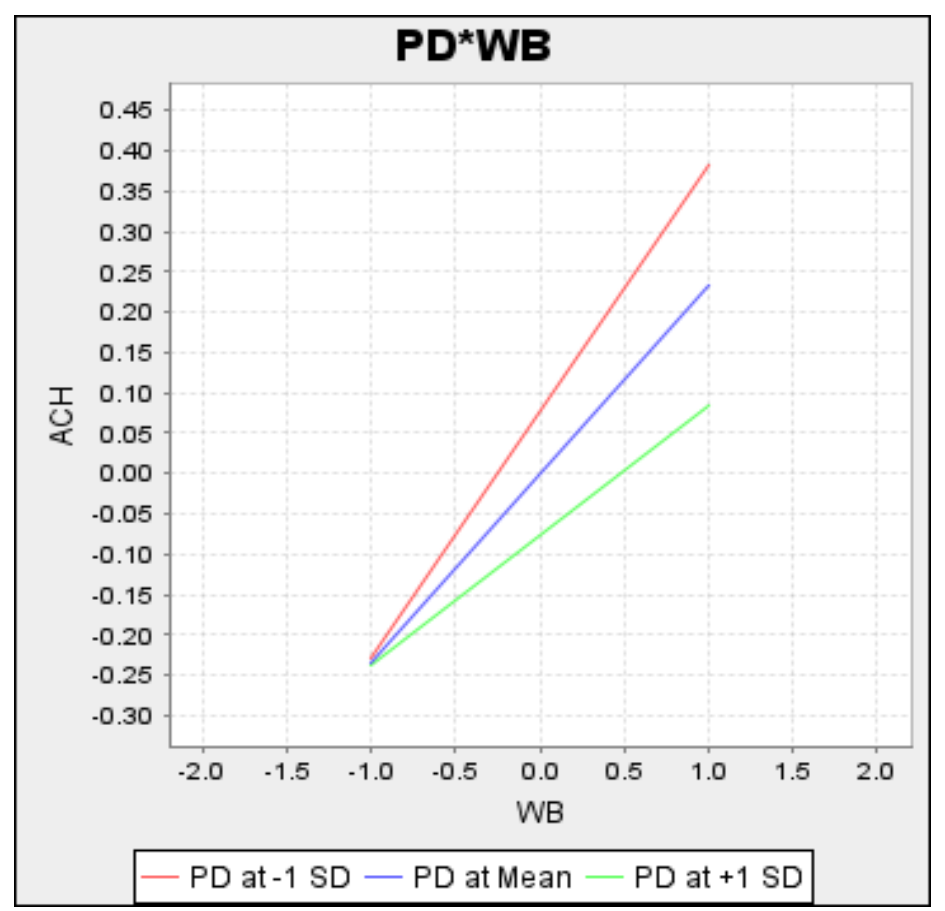

Figure 3 shows that the line labeled for a higher level of PD has a steeper gradient than the lower level of PD, negatively impacting the association of WB with $A C H$. This gradient means that the more the level of perceived discrimination, the less is the sense of achievement among the immigrant students. Thus, hypothesis 5 was supported. 
Table 3

Hypothesis Testing Results

\begin{tabular}{llcccc}
\hline & Hypotheses & Std. Beta & t-Value & p-values & Findings \\
\hline H1a & $\mathrm{CP} \rightarrow \mathrm{ACH}$ & 0.214 & 4.262 & 0.001 & Supported \\
H1b & $\mathrm{SC} \rightarrow \mathrm{ACH}$ & 0.219 & 4.345 & 0.000 & Supported \\
H2a & $\mathrm{CP} \rightarrow \mathrm{WB}$ & 0.259 & 5.659 & 0.000 & Supported \\
H2b & $\mathrm{SC} \rightarrow \mathrm{WB}$ & 0.267 & 5.737 & 0.000 & Supported \\
H3 & $\mathrm{WB} \rightarrow \mathrm{ACH}$ & 0.227 & 4.807 & 0.000 & Supported \\
H4a & $\mathrm{CP} \rightarrow \mathrm{WB} \rightarrow \mathrm{ACH}$ & 0.201 & 4.087 & 0.003 & Supported \\
H4b & $\mathrm{SC} \rightarrow \mathrm{WB} \rightarrow \mathrm{ACH}$ & 0.238 & 5.124 & 0.000 & Supported \\
H5 & $\mathrm{PD} * \mathrm{WB} \rightarrow \mathrm{ACH}$ & 0.196 & 3.871 & 0.005 & Supported \\
\hline
\end{tabular}

Where: $C P=$ Cultural Pluralism; $S C=$ Social Connectedness; $W B=$ Social Wellbeing; ACH $=$ Achievement $P D=$ Perceived Discrimination

Figure 4

Full Structural Model

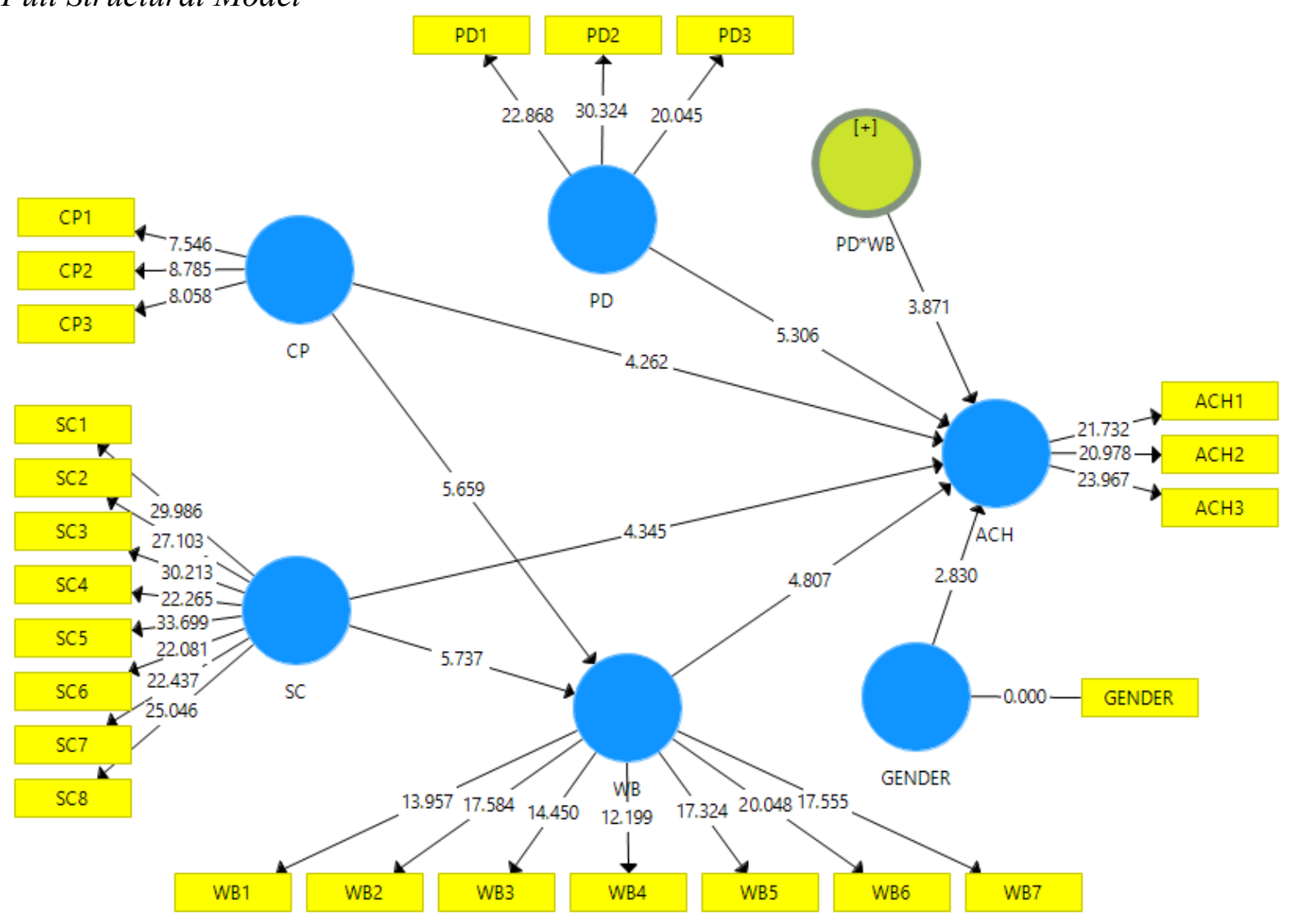

\section{Discussion}

The main aim of this study was to evaluate immigrant students' wellbeing and academic achievement based on their perception of cultural pluralism and social connectedness. Also, the negative moderating impact of perceived discrimination arising based on cultural diversity among immigrant students on their achievement was assessed. Moreover, the current study advances social psychology theory by integrating cultural pluralism, social connectedness, 
wellbeing, achievement (as positive factors), and perceived discrimination (as a negative factor) in a single comprehensive framework in a cultural diversity context.

The results showed a positive and significant impact of cultural pluralism on students' achievements. These results align with the Oczlon et al. (2021), representing the importance of providing students with a sense of belongingness to the host country and educational institutions to concentrate on their studies without any tension and feelings of disrespect. Likewise, social connectedness was found to impact student achievement positively and significantly. These results advance the findings of Chen et al. (2021) that providing immigrant students a feeling of connectedness motivates them and satisfies them with the learning process by adding the positive impact of social connectedness on students' achievement.

Although social well-being is a socio-affective variable embedded in the students' benefit context (Zhang et al., 2021), it has been less explored in immigrant students' cultural diversity and achievement context. Therefore, adding to the body of knowledge, the current study's findings reflect the importance of social wellbeing in transmitting the positive impact of cultural pluralism and social connectedness in immigrant students' achievements. Previously, wellbeing has been particularly linked with cultural adjustments and student and goal accomplishments. At the same time, the current study suggests its importance in communicating the socially connected school environment and a climate of cultural respect in achieving high grades among immigrant students.

Finally, the current study advances the existing literature regarding the negative consequences of perceived discrimination in diverse cultural contexts by examining its interactive effect on social wellbeing. The results show that perceived discrimination not only negatively impacts student academic achievement (Guerra et al., 2019; Sadeghi et al., 2018) but also reduces the positive impact of social wellbeing on immigrant students' academic achievements. Therefore, previous studies have linked poor school and psychological adjustments (Hood, Bradley, \& Ferguson, 2017). This finding further shows that discrimination destroys students' intellectual capacity to compete with fellow students and perform their best. It also shows that even if students are satisfied with their abilities and have a positive attitude towards studies when they perceive being discriminated based on their belongingness with different cultures, their ability to perform decreases, and they achieve less.

\section{Practical Implications}

The current study offers valuable insights for policymakers and practitioners in developing and developed nations.

- First, the current study revealed the positive impact of cultural pluralism on immigrant students' social wellbeing and achievements. It shows that while dealing with students from diverse backgrounds, institutions/universities representatives, especially teachers, should ensure that every student receives the same attention to make them feel part of the whole system.

- Second, the positive impact of social connectedness on students' wellbeing and achievement reflects the importance of creating an environment of helpfulness and sharing each other's success. Also, students should be encouraged to study in groups, share their expertise with other students, and frequently communicate with their fellows to create a socially harmonious environment where no one feels isolated.

- Moreover, institutional authorities should organize frequent educational activities in the form of seminars and healthy competition to bring students closer and frequently communicate to feel like a part of a collective system. 
- Third, students' wellbeing as an underlying mechanism reveals that cultural pluralism and social connectedness directly impact the students' achievement and involve certain underlying mechanisms that facilitate transferring them into students' achievement. Hence, student satisfaction with the institution/university environment, teachers' attitudes, and facilities are equally important, along with providing them with a favorable climate to excel in their academic carrier.

- Finally, the moderating impact of perceived discrimination shows that it not only negatively impacts students' achievement but also decreases the positive impact of students' wellbeing on their achievement. Therefore, it is of utmost importance to take such measures that promote a culture of harmony and impartiality. This will help all students concentrate and remain focused on their educational goals rather than wasting their time dealing with discriminatory factors.

\section{Limitations and Future Research Directions}

The current study has some limitations that future researchers should consider, along with several theoretical and practical significances. First, the current study considered immigrants based on their parents' birth in a country other than Indonesia (currently living and studying). However, their self-identification was not given much attention. Therefore, the possibility arises that some students might not consider themselves to be immigrants, which could be true for second-generation immigrants due to the lack of experience in the migration process. Hence, there can be predictive differences for the impact of cultural pluralism and social connectedness for students who self-identify as immigrants and those who do not participate in the survey, although they have some migration background.

Second, this study did not separately consider cultural and ethnic groups and the impact of study variables on their achievements. Thus, future studies should carefully select respondents and consider the ethnic or cultural identity to check the impact of cultural pluralism on immigrant students' wellbeing and achievements.

Third, this study relied on self-reported measures to examine the impact of cultural pluralism and social connectedness on students' positive outcomes. In the future, more data sources like school administrators and teachers can be considered to create more generalized results. As previous research reveals the difference in perception of teachers and students (Bardach et al., 2019), it can also be informative to check whether it is also true in cultural pluralism and social connectedness context.

Finally, the current study examined the moderating role of perceived discrimination in decreasing the impact of wellbeing on students' achievement. In contrast, future researchers should examine the contingent impact of students' attitudes and commitments in between the association of wellbeing and academic achievements to bring some interesting policy insights.

\section{Conclusion}

The environment of cultural pluralism captures a climate where cultural group differences are respected by providing adequate opportunities for learning to students with different cultural backgrounds (Schachner et al., 2019). Likewise, social connectedness depicts the close relationship with the social world, including friends, family, peers, society, and community (Liu, 2019). Therefore, many scholars reported the importance of investigating these constructs in immigrant students' wellbeing and achievement context (Oczlon et al., 2021; Smith et al., 2020). Hence, considering the importance of dealing with cultural diversity, this 
study examined the impact of cultural pluralism and social connectedness on immigrant students' social wellbeing and resultant achievement. This study also investigated the moderating effect of perceived discrimination in decreasing the effect of the students' wellbeing in generating positive outcomes like students' achievement. The results revealed the positive impact of cultural pluralism and social connectedness on immigrant students' social wellbeing leading to high achievements, thus, demonstrating the importance of respecting the cultural differences and different ethnic backgrounds and facilitating the students to perform at their best possible level to achieve the maximum level of success. The results also showed that the positive influence of immigrant students' social wellbeing on their achievements decreases in the presence of perceived discrimination as a moderator. Hence, measures should be taken at authoritative levels to decrease the discrimination among the local and immigrant students to make them feel a part of the same community to enhance their achievement levels.

\section{References}

Aliyyah, R. R., Rachmadtullah, R., Samsudin, A., Syaodih, E., Nurtanto, M., \& Tambunan, A. R. S. (2020). The perceptions of primary school teachers of online learning during the COVID-19 pandemic period: A case study in Indonesia. Journal of Ethnic and Cultural Studies, 7(2), 90-109. http://dx.doi.org/10.29333/ejecs/388

Banks, J. A. (2015). Cultural diversity and education: Foundations, curriculum, and teaching. Routledge.

Bardach, L., Yanagida, T., Schober, B., \& Lüftenegger, M. (2019). Students' and teachers' perceptions of goal structures-Will they ever converge? Exploring changes in studentteacher agreement and reciprocal relations to self-concept and achievement. Contemporary Educational Psychology, 59, Article 101799. https://doi.org/10.1016/ j.cedpsych.2019.101799

Bender, M., van Osch, Y., Sleegers, W., \& Ye, M. (2019). Social support benefits psychological adjustment of international students: Evidence from a meta-analysis. Journal of CrossCultural Psychology, 50(7), 827-847. https://doi.org/ 10.1177/0022022119861151

Benita, M. S. (2021). Are the student migrants satisfied with life? Effect of acculturative stress and perceived discrimination. International Journal of Education Economics and Development, 12(1), 79-96. https://doi.org/10.1504/IJEED.2021.111658

Binfet, J.-T. (2017). The effects of group-administered canine therapy on university students' wellbeing: A randomized controlled trial. Anthrozoös, 30(3), 397-414. https://doi.org/10.1080/08927936.2017.1335097

Brenick, A., Schachner, M. K., \& Jugert, P. (2018). Help or hindrance? Minority versus majority cross-ethnic friendships altering discrimination experiences. Journal of Applied Developmental Psychology, 59, 26-35. https://doi.org/10.1016/j.appdev.2018.04.006

Celeste, L., Baysu, G., Phalet, K., Meeussen, L., \& Kende, J. (2019). Can school diversity policies reduce belonging and achievement gaps between minority and majority youth? Multiculturalism, colorblindness, and assimilationism assessed. Personality and Social Psychology Bulletin, 45(11), 1603-1618. https://doi.org/10.1177/ 0146167219838577

Chen, A. S.-y., Lin, G.-h., \& Yan, H.-w. (2021). Staying connected: Effects of social connectedness, cultural intelligence, and socioeconomic status on overseas students' life satisfaction. International Journal of Intercultural Relations, 83, 151-162. https://doi.org/10.1016/j.ijintre1.2021.06.002

Cojuharenco, I., Cornelissen, G., \& Karelaia, N. (2016). Yes, I can: Feeling connected to others increases perceived effectiveness and socially responsible behavior. Journal of Environmental Psychology, 48, 75-86. https://doi.org/https://doi.org/10.1016/ j.jenvp.2016.09.002 
Dalle, J., \& Ariffin, A. M. (2018). The impact of technologies in teaching interaction design. Journal of Advanced Research in Dynamical and Control Systems, 10(4 Special Issue), 1779-1783.

Dalle, J., Hairudinor, H., Baharuddin, B., Sriadhi, \& Chandra, T. (2020). Does it unrest alter the effect of risk-taking attitude on the organization's performance? Journal of Security and Sustainability Issues, 9(5), 158-172.

Dalle, J., Hastuti, D., \& Akmal, F. (2021). Evaluation of Peatland Suitability for Rice Cultivation using Matching Method. Polish Journal of Environmental Studies, 30(3), 2041-2047. https://doi.org/10.15244/pjoes/127420

Dalle, J., Siyoto, S., Astika, N. D., Negara, D. J., Chandra, T., \& Anam, K. (2020). Moderating role of IT adoption and mechanism of dynamic capabilities on Indonesian pharmaceutical firms performance. Systematic Reviews in Pharmacy, 11(9), 982-992. https://doi.org/10.31838/srp.2020.9.142

Dengechi, B., Worku, N., \& Mikre, F. (2021). Comparing the psychological wellbeing of the Manjo ethnic minority with the non-Manjo ethnic group in Kaffa Zone, Ethiopia. Journal of Ethnic and Cultural Studies, 8(2), 21-38. doI:10.29333/ejecs/591

Diener, E., \& Scollon, C. (2003, October 23-25). Subjective wellbeing is desirable, but not the summum bonum. [Paper presentation]. University of Minnesota Interdisciplinary Workshop on Well-Being, Minneapolis.

Filippello, P., Buzzai, C., Costa, S., Orecchio, S., \& Sorrenti, L. (2020). Teaching style and academic achievement: The mediating role of learned helplessness and mastery orientation. Psychology in the Schools, 57(1), 5-16. https://doi.org/10.1002/pits.22315

Guerra, R., Rodrigues, R. B., Aguiar, C., Carmona, M., Alexandre, J., \& Lopes, R. C. (2019). School achievement and wellbeing of immigrant children: The role of acculturation orientations and perceived discrimination. Journal of School Psychology, 75, 104-118. https://doi.org/10.1016/j.jsp.2019.07.004

Hachfeld, A., Hahn, A., Schroeder, S., Anders, Y., Stanat, P., \& Kunter, M. (2011). Assessing teachers' multicultural and egalitarian beliefs: The teacher cultural beliefs scale. Teaching and Teacher Education, 27(6), 986-996. https://doi.org/10.1016/ j.tate.2011.04.006

Henseler, J., Ringle, C. M., \& Sarstedt, M. (2015). A new criterion for assessing discriminant validity in variance-based structural equation modeling. Journal of the Academy of Marketing Science, 43(1), 115-135. https://doi.org/10.1007/s11747-014-0403-8

Henseler, J., Ringle, C. M., \& Sinkovics, R. R. (2009). The use of partial least squares path modeling in international marketing. In R. R. Sinkovics \& P.N. Ghauri (Eds.), Advances in mnternational marketing, 20 (pp. 277-319). Emerald Publishing.

Hutabarat, A. (2020). Indonesian political policy in overcoming illegal immigrant problems in Indonesia. International Journal on Social Science, Economics and Art, 10(2), 96-103. https://doi.org/10.35335/ijosea.v10i2.17

Hysa, E. (2020). Impact of cultural diversity on Western Balkan countries' performance. Journal of Ethnic and Cultural Studies, 7(1), 20-40. http://dx.doi.org/10.29333/ejecs/292

Karyanta, N. A. (2021). Measuring acculturative stress and general self-rated health of internal migrant students in Indonesia: Considering Social Identity Theory. In Proceedings of the International Conference on Psychological Studies (ICPSYCHE 2020) (pp. 60-67). Atlantis Press. https://doi.org/10.2991/assehr.k.210423.009 
Keyes, C. L. (2006). Subjective wellbeing in mental health and human development research worldwide: An introduction. Social Indicators Research, 77(1), 1-10. https://doi.org/10.1007/s11205-005-5550-3

Keyes, C. L. M. (1998). Social wellbeing. Social Psychology Quarterly, 61(2), 121-140. https://doi.org/10.2307/2787065

Kim, Y., Mok, S. Y., \& Seidel, T. (2020). Parental influences on immigrant students' achievement-related motivation and achievement: A meta-analysis. Educational Research Review, 30, Article 100327. https://doi.org/10.1016/j.edurev.2020.100327

Lee, R. M., \& Robbins, S. B. (1995). Measuring belongingness: The social connectedness and the social assurance scales. Journal of Counseling Psychology, 42(2), 232-241. https://doi.org/10.1037/0022-0167.42.2.232

Li, C. (2020). A positive psychology perspective on Chinese EFL students' trait emotional intelligence, foreign language enjoyment and EFL learning achievement. Journal of Multilingual and Multicultural Development, 41(3), 246-263. https://doi.org/10.1080/ 01434632.2019.1614187

Liu, M. (2019). Predicting effects of demographic, linguistic and psychological variables on university international students' intercultural communication sensitivity. Journal of Ethnic and Cultural Studies, 6(3), 123-133. doi:10.29333/ejecs/277

Locks, A. M., Hurtado, S., Bowman, N. A., \& Oseguera, L. (2008). Extending notions of campus climate and diversity to students' transition to college. The Review of Higher Education, 31(3), 257-285. doi:10.1353/rhe.2008.0011

López, V., Oyanedel, J. C., Bilbao, M., Torres, J., Oyarzún, D., Morales, M., Ascorra, P., \& Carrasco, C. (2017). School achievement and performance in Chilean high schools: the mediating role of subjective wellbeing in school-related evaluations. Frontiers in Psychology, 8, 1189. https://doi.org/10.3389/fpsyg.2017.01189

Luczak, C., \& Kalbag, A. (2018). The appropriateness and effectiveness of cross-aged peer mentoring in the learning environment. International Journal of Humanities, Arts and Social Sciences, 4(2), 76-84. https://doi.org/https://dx.doi.org/10.20469/ijhss.4.10003-2

Luhmann, M., Hofmann, W., Eid, M., \& Lucas, R. E. (2012). Subjective wellbeing and adaptation to life events: A meta-analysis. Journal of Personality and Social Psychology, 102(3), 592-615. https://doi.org/10.1037/a0025948

Mansoor, M. (2021a). Citizens' trust in government as a function of good governance and government agency's provision of quality information on social media during COVID19. Government Information 101597. https://doi.org/https://doi.org/10.1016/j.giq.2021.101597

Mansoor, M. (2021b). An interaction effect of perceived government response on COVID-19 and government agency's use of ICT in building trust among citizens of Pakistan. Transforming Government: People, Process and Policy. Advance online publication. https://doi.org/https://doi.org/10.1108/TG-01-2021-0002

Mansoor, M., \& Noor, U. (2019). Determinants of green purchase intentions: Positive word of mouth as moderator. Journal of Business \& Economics, 11(2), 143-160.

Manuela, S., \& Sibley, C. G. (2015). The Pacific Identity and Wellbeing Scale-Revised (PIWBS-R). Cultural Diversity and Ethnic Minority Psychology, 21(1), 146-155. https://doi.org/10.1037/a0037536

Mason, A. (2016). Justice, feasibility, and ideal theory: A pluralist approach. Social Philosophy and Policy, 33(1-2), 32-54. doi:10.1017/S0265052516000388

Motti-Stefanidi, F. (2018). Resilience among immigrant youth: The role of culture, development and acculturation. Developmental Review, 50(Part A), 99-109. https://doi.org/10.1016/j.dr.2018.04.002 
Nedal, O. A., \& Alcoriza, M. G. O. (2018). Challenges in education: The untold story of students in Lanao Kapanglao, Glan, Sarangani province. Journal of Advances in Humanities and Social Sciences, 4(3), 118-126. https://doi.org/https://doi.org/ 10.20474/jahss-4.3.1

Newton, D. C., LaMontagne, A., \& Tomyn, A. (2021). Exploring the challenges and opportunities for improving the health and wellbeing of international students: Perspectives of professional staff at an Australian University. JANZSSA-Journal of the Australian and New Zealand Student Services Association, 29(1), 74-92.

Noor, U., Mansoor, M., \& Rabbani, S. (2021). Brand hate and retaliation in Muslim consumers: does offensive advertising matter? Journal of Islamic Marketing. Advance online publication. https://doi.org/https://doi.org/10.1108/JIMA-10-2020-0316

Oczlon, S., Bardach, L., \& Lüftenegger, M. (2021). Immigrant adolescents' perceptions of cultural pluralism climate: Relations to self-esteem, academic self-concept, achievement, and discrimination. New Directions for Child and Adolescent Development. Advance online publication. https://doi.org/10.1002/cad.20412

Oweis, T. I. (2018). Effects of using a blended learning method on students' achievement and motivation to learn English in Jordan: A pilot case study. Education Research International, 2018, Article 7425924. https://doi.org/10.1155/2018/7425924

Papadopoulou, V., Theodosiadou, K., \& Palaiologou, N. (2020). Teachers' personal theories of teaching: Managing cultural diversity in mainstream public primary schools in Greece. Journal of Ethnic and Cultural Studies, 7(2), 195-211. http://dx.doi.org/10.29333/ejecs/375

Sadeghi, S., Sajjadi, S. N., Nooshabadi, H. R., \& Farahani, M. J. (2018). Social-cultural barriers of Muslim women athletes: Case study of professional female athletes in Iran. Journal of Management Practices, Humanities and Social Sciences, 2(1), 6-10.

Samad, S., Nilashi, M., \& Ibrahim, O. (2019). The impact of social networking sites on students' social wellbeing and academic performance. Education and Information Technologies, 24(3), 2081-2094. https://doi.org/10.1007/s10639-019-09867-6

Sawatsuk, B., Darmawijaya, I. G., Ratchusanti, S., \& Phaokrueng, A. (2018). Factors determining the sustainable success of community-based tourism: Evidence of good corporate governance of Mae Kam Pong Homestay, Thailand. International Journal of Business and Economic Affairs, 3(1), 13-20. https://doi.org/10.24088/IJBEA-201831002

Schachner, M. K., Noack, P., Van de Vijver, F. J., \& Eckstein, K. (2016). Cultural diversity climate and psychological adjustment at school-Equality and inclusion versus cultural pluralism. Child Development, 87(4), 1175-1191. https://doi.org/10.1111/ cdev.12536

Schachner, M. K., Schwarzenthal, M., Van De Vijver, F. J., \& Noack, P. (2019). How all students can belong and achieve: Effects of the cultural diversity climate amongst students of immigrant and nonimmigrant background in Germany. Journal of Educational Psychology, 111(4), 703-716. https://doi.org/10.1037/edu0000303

Schotte, K., Stanat, P., \& Edele, A. (2018). Is integration always most adaptive? The role of cultural identity in academic achievement and in psychological adaptation of immigrant students in Germany. Journal of Youth and Adolescence, 47(1), 16-37. https://doi.org/10.1007/s10964-017-0737-x

Smith, L. V., Wang, M.-T., \& Hill, D. J. (2020). Black youths' perceptions of school cultural pluralism, school climate and the mediating role of racial identity. Journal of School Psychology, 83, 50-65. https://doi.org/10.1016/j.jsp.2020.09.002 
Stone, S., \& Logan, A. (2018). Exploring students' use of the social networking tite WhatsApp to foster connectedness in the online learning experience. Irish Journal of Technology Enhanced Learning Ireland, 3(1), 42-55.

Sueca, I. N., Sumertha, I. N., \& Winaja, I. W. (2021). A time-lag study on perceived threat of COVID-19 in Hindu religious community: Moderating role of Hindu religious coping. Journal of Ethnic and Cultural Studies, 8(3), 217-243.

Sun, X., Hall, G. C. N., DeGarmo, D. S., Chain, J., \& Fong, M. C. (2021). A longitudinal investigation of discrimination and mental health in Chinese international students: The role of social connectedness. Journal of Cross-Cultural Psychology, 52(1), 61-77. https://doi.org/10.1177/0022022120979625

Wang, M.-T., Degol, J. L., Amemiya, J., Parr, A., \& Guo, J. (2020). Classroom climate and children's academic and psychological wellbeing: A systematic review and metaanalysis. Developmental Review, 57, Article 100912. https://doi.org/10.1016/ j.dr.2020.100912

Wasike, C. N. (2017). Financial regulation as moderating influence of corporate governance, institutional quality, human capital and firm size on financial institutions performance in Kenya. Journal of Administrative and Business Studies, 3(6), 292-304. Available at SSRN: https://ssrn.com/abstract $=3744876$

Wei, M., Liang, Y.-S., Du, Y., Botello, R., \& Li, C.-I. (2015). Moderating effects of perceived language discrimination on mental health outcomes among Chinese international students. Asian American Journal of Psychology, 6(3), 213-222. https://doi.org/10.1037/aap0000021

Wu, B., \& Ida, A. K. (2018). Ethnic diversity, religion, and opinions toward legalizing abortion: The case of Asian Americans. Journal of Ethnic and Cultural Studies, 5(1), 94-109.

Yamamori, K. (2019). Classroom practices of low-cost STEM education using scratch. Journal of Advanced Research in Social Sciences and Humanities Volume, 4(6), 192-198. https://doi.org/https://dx.doi.org/10.26500/JARSSH-04-2019-0601

Yue, Y., \& Le, Q. (2012). International students' social engagement and social wellbeing in an Australian regional area. International Journal of Health, Wellness \& Society, 2(3).

Zhang, Y., Zhao, W., Jiang, T., Chen, X., \& Luo, Y. (2021). Examining the relationship between social class and wellbeing in Chinese adolescents: The mediating role of basic psychological needs. Youth \& Society. Advance online publication. https://doi.org/10.1177/0044118X211001101

\section{Notes on Contributor}

H. Abubakar H.M. is a Senior Lecturer at the Faculty of Ushuludin, Adab, and Da'wah IAIN Palangka Raya. He completed his Bachelor's Study at the Faculty of Adab IAIN Alauddin Ujung Pandang, now UIN Alauddin Makassar (1980); Master of Sociology of Islamic Society, University of Muhammadiyah Malang (1999) and Doctoral Studies in Islamic Studies UIN Sunan Kalijaga Yogyakarta (2015). One of his researches in 2018 and 2019 entitled Sesanti "Isen Mulang" Symbol of the Spirit of the Dayak Community in responding to the Discourse of Moving the State Capital to Palangka Raya City. 